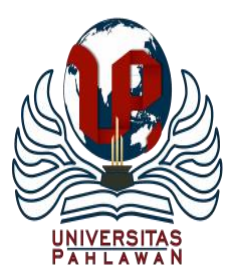

Jurnal Abdidas Volume 2 Nomor 4 Tahun 2021 Halaman 1014-1020

JURNAL ABDIDAS

http://abdidas.org/index.php/abdidas

\title{
Edukasi Literasi Digital pada Remaja dalam Menangkal Cyberbullying
}

\author{
Merry Fridha Tri Palupi ${ }^{1}$, Fitri Norhabiba ${ }^{2}$ \\ Ilmu Komunikasi, FISIP, Untag Surabaya, Indonesia ${ }^{1,2}$ \\ E-mail: Merry.fridha@untag-sby.ac.id ${ }^{1}$ fitrinorhabiba@gmail.com $^{2}$
}

\begin{abstract}
Abstrak
Revolusi industri 4.0 merupakan transformasi digital yang digambarkan sebagai sebuah pertukaran data dalam bidang teknologi komunikasi di mana digital dan fisik bersatu membuat pertukaran data secara real time. Demikian canggihnya, sehingga perubahan teknologi ini harus diimbangi dengan pola perilaku remaja sebagai pengguna terbanyak kedua dalam penggunaan media digital yaitu sebesar 18,72\% (bps.go.id, diakses Agustus 2021). Dengan demikian, remaja harus bijak dalam bermedia. Kegiatan literasi digital merupakan langkah penting dan sesuai dengan program Kominfo yang menargetkan 12,5 juta masyarakat Indonesia terliterasi digital setiap tahunnya, sehingga 50 juta masyarakat akan terliterasi pada tahun 2024 (Agustini, 2021). Melihat pentingnya kegiatan tersebut, maka tim pengabdi melaksanakan kegiatan ini dengan mitra komunitas Cacak Yuk Lumajang yaitu sebuah komunitas yang mewadahi Putra-putri Duta Wisata Kabupaten Lumajang dan berada di bawah naungan Dinas Pariwisata dan Kebudayaan Kabupaten Lumajang. Tim pengabdi berfokus pada pengenalan mengenai literasi digital dan bagaimana menangkal cyberbullying dengan bentuk kegiatan berupa workshop dan sharing session. Kegiatan ini di ikuti oleh 54 peserta. Sebelum kegiatan, peserta mengisi pretest dan setelah kegiatan peserta mengisi post-test. Dari hasil tersebut ditemukan 17 orang menjadi pelaku dan korban cyberbullying. Dan di akhir kegiatan pemahaman peserta akan literasi digital semakin bertambah dan peserta lebih memahami cara untuk menangkal cyberbullying.
\end{abstract}

Kata kunci: edukasi, literasi digital, cyberbullying

\section{Abstract}

The industrial revolution 4.0 is a digital transformation which is described as an exchange of data in the field of communication technology where digital and physical unite to make data exchange in real time. So sophisticated, so that this technological change must be balanced with the behavior patterns of teenagers as the second largest user in the use of digital media, which is 18.72\% (bps.go.id downloaded in August, 2021), thus teenagers must be wise in media. Digital literacy activities are an important step and are in accordance with the Kominfo program which targets 12.5 million Indonesians to be digitally literate every year, so that 50 million people will be literate by 2024 (Agustini, 2021). Seeing the importance of this activity, the service team carried out this activity with the Cacak Yuk Lumajang partner community, a community that accommodates the sons and daughters of Lumajang Regency tourism ambassadors and is under the auspices of the Lumajang Regency Tourism and Culture office. The service team focuses on introducing digital literacy and how to prevent cyberbullying through activities in the form of workshops and sharing sessions. This activity was attended by 54 participants. Before the activity the participants filled out the pretest and after the activity the participants filled out the posttest. From these results, 17 people were found to be perpetrators and victims of cyberbullying. And at the end of the participants' understanding of digital literacy is increasing and participants are more aware of how to prevent cyberbullying

Keywords: education, digital literacy, cyberbullying

Copyright (c) 2021 Merry Fridha Tri Palupi, Fitri Norhabiba

$\triangle$ Corresponding author

Address : Untag Surabaya

Email : Merry.fridha@untag-sby.ac.id

DOI : https://doi.org/10.31004/abdidas.v2i4.408

ISSN 2721-9224 (Media Cetak)

ISSN 2721- 9216 (Media Online) 
1015 Edukasi Literasi Digital pada Remaja dalam Menangkal Cyberbullying-Merry Fridha Tri Palupi, Fitri Norhabiba

DOI: https://doi.org/10.31004/abdidas.v2i4.408

\section{PENDAHULUAN}

Perkembangan dunia digital semakin massif dari hari ke hari. Teknologi sering di ibaratkan seperti pisau bermata dua. Di satu sisi jelas teknologi banyak membantu kehidupan masyarakat, seperti misalnya bidang bisnis dan pendidikan menjadi lebih mudah tanpa adanya penyekatan ruang dan waktu. Sedangkan, di sisi lain, teknologi seringkali menjadi boomerang bagi orang yang tidak bijak dalam menggunakannya.

Hasil dari penelitian Sumiati dan Siti Satriani mengungkapkan bahwa teknologi yang berasal dari dunia barat telah membawa banyak kemajuan serta kesejahteraan pada kehidupan masyarakat dan seolah-olah menjanjikan kehidupan yang lebih baik. Namun, karena kemajuan tersebut tidak diimbangi dengan perilaku masyarakat maka menjadi tidak seimbang (Sumiati, Satriani, 2018). Ketidakseimbangan yang dimaksud adalah bagaimana perilaku pengguna tekhnologi yang tidak bijak dalam menggunakan media di mana kita seringkali melihat banyaknya perilaku cyberbullying yang dilakukan remaja akibat ketidakbijakan dalam menggunakan media digital.

Berdasarkan rilis yang disampaikan kompas.com, pada tahun 2021 pengguna internet di Indonesia menembus angka 202 juta jiwa. Jumlah tersebut meningkat $15,5 \%$ dari tahun sebelumnya. Smartphone merupakan perangkat yang paling banyak digunakan. Dari data yang dihimpun, pada rentang usia 16-64 tahun hampir semua memiliki smartphone yaitu 98, 3\%. Hal ini disinyalir karena smartphone paling mudah digunakan dan lebih fleksibel untuk dibawa bepergian. Dalam laporan yang sama pengguna smartphone di Indonesia memiliki rata-rata waktu 8 jam sehari untuk berselancar di internet (Galuh, 2021).

Internet telah banyak merubah tata kehidupan masyarakat, hal ini dikarenakan adanya revolusi industri. Revolusi industri 4.0 merupakan transformasi digital yang digambarkan sebagai sebuah pertukaran data dalam bidang teknologi komunikasi yang sangat canggih. Di era ini, cyber digital dan fisik bersatu membuat pertukaran data secara real time. Demikian canggihnya, sehingga perubahan teknologi ini harus diimbangi dengan perubahan pola perilaku masyarakat terutama remaja sebagai pengguna aktif terbanyak kedua dalam penggunaan perangkat digital.

Kemajuan tehnologi digital, ternyata tidak diikuti dengan kecerdasan dalam menggunakan media digital. Hal ini seperti disampaikan Qory Qurrotun A'Yuni dalam penelitiannya yang berjudul Literasi Digital Remaja di Kota Surabaya (Studi Deskriptif tentang Tingkat Kompetensi Literasi Digital pada Remaja SMP, SMA dan Mahasiswa di Kota Surabaya). Hasil penelitian Qory menunjukkan bahwa tingkat evaluasi remaja Surabaya terhadap konten digital belum menggembirakan. Remaja cenderung acuh tak acuh dan enggan verifikasi pada informasi yang didapat dari media digital (A'Yuni, 2014).

Hal ini membawa keprihatinan sehingga sosialisasi literasi digital menjadi perhatian akademisi dan menjadikannya sebagai agenda dalam kegiatan pengabdian masyarakat. Seperti misalnya Gaol, L Faraswaycen yang melakukan pengabdian sosialisasi literasi digital pada Remaja 
1016 Edukasi Literasi Digital pada Remaja dalam Menangkal Cyberbullying-Merry Fridha Tri Palupi, Fitri Norhabiba

DOI: https://doi.org/10.31004/abdidas.v2i4.408

Karang Taruna Kelurahan Tanjung Priok, Jakarta Utara (Gaol, L Faraswaycen, 2020). Pengabdian lain serupa juga dilakukan oleh Alfrina Mewengkang dan kawan-kawan dari Universitas Negeri Manado dengan judul Pengabdian Literasi Digital: Pelatihan bagi Pemuda Gereja BMIM Bukit Zaitun Sea Mitra (Mewengkang, Alfrina, 2019). Theresia Herlina Rochadiani, dkk yang mengadakan pengabdian dengan judul Peningkatan Literasi Digital pada Masa Covid-19 (Rochadiani, Herlina, 2020). Serta masih banyak lagi kegiatan pengabdian masyarakat yang dilakukan oleh dosen-dosen seluruh Indonesia.

Maka dengan banyaknya pengabdian dengan tema yang sama pengabdi melihat bahwa permasalahan literasi digital merupakan hal yang sangat mendesak untuk di sosialisasikan. Sehingga tim pengabdi melakukan kegiatan pengabdian yang diberi judul Edukasi Literasi Digital dalam Menangkal Cyberbullying yang bertujuan untuk memberikan pemahaman mendalam mengenai literasi digital agar komunitas Cacak dan Yuk Lumajang sebagai mitra kegiatan dapat menangkal cyberbullying.

\section{METODE}

Edukasi literasi digital dilakukan pada Paguyuban Cacak Yuk Lumajang. Paguyuban ini dibawah naungan Dinas Pariwisata dan Kebudayaan Kabupaten Lumajang yang merupakan alumni dari ajang pemilihan putra putri terbaik Lumajang yang berkompetisi pada program pariwisata daerah Lumajang. Sebagai Duta Wisata Kabupaten Lumajang, anggota Paguyuban Cacak Yuk Lumajang merupakan opinion leader dan memiliki pengaruh bagi remaja di Kabupaten Lumajang. Sebagai opinion leader tentu anggota paguyuban harus peka dan bijak dalam menggunakan media digital. Diharap dengan memahami literasi digital, anggota paguyuban akan ikut mengkampanyekan literasi digital serta mengkampanyekan gerakan anti cyberbullying secara lebih luas lagi karena penggunaan internet secara masif harus dibarengi dengan literasi digital yang memadai.

Paguyuban ini memiliki kegiatan positif yaitu sebagai ajang pengembangan diri para anggota, selain itu para anggota juga diasah untuk lebih berempati pada kehidupan masyarakat sekitar. Dengan memiliki anggota sejumlah 60 orang anggota paguyuban aktif dalam melakukan kegiatan-kegiatan sosial. Anggota paguyuban berusia sekitar 15 tahun hingga 28 tahun, dengan status sebagai pelajar atau mahasiswa. Sebagai remaja milineal sudah pasti anggota paguyuban aktif menggunakan media sosial.

Dari ke 60 anggota Paguyuban Cacak dan Yuk Lumajang, 50 anggota mengikuti acara edukasi literasi digital ini. Literasi digital merupakan hal yang sangat penting di era teknologi informasi yang semakin canggih agar masyarakat dapat berpartisipasi secara positif. Bisa dilihat bahwa saat ini begitu banyak informasi bohong/hoax yang disebarkan di internet. Maka dengan pemahaman literasi digital yang baik, peserta edukasi literasi digital tidak akan mudah percaya dengan berita-berita yang belum tentu kebenarannya, serta bijak dalam menyebarkan informasi di media digital dan dapat menangkal cyberbullying. Dalam memahami literasi digital, 
maka terdapat delapan elemen litersi digital yang disampaikan Belshaw, (2011) dalam tesisnya What is 'Digital Literacy'? yaitu:

1. Kultural, yaitu pemahaman ragam konteks pengguna dunia digital;

2. Kognitif, yaitu daya pikir dalam menilai konten;

3. Konstruktif, yaitu reka cipta sesuatu yang ahli dan aktual;

4. Komunikatif, yaitu memahami kinerja jejaring dan komunikasi di dunia digital;

5. Kepercayaan diri yang bertanggung jawab;

6. Kreatif, melakukan hal baru dengan cara baru;

7. Kritis dalam menyikapi konten;

8. Bertanggung jawab secara sosial.

Maka untuk mencapai delapan elemen tersebut, dilakukan kegiatan pengabdian dengan metode sebagai berikut:

1. Ceramah seputar pemahaman dasar tentang penggunaan media digital dan UU ITE;

2. Sharing session seputar cyberbullying;

3. Roleplaying cara menangkal cyberbullying;

4. Pretest dan post-test untuk mengukur pemahaman literasi digital dan untuk mengetahui bagaimana perilaku peserta dalam menggunakan media digital;

5. Pendampingan intensif bagi peserta yang terindikasi menjadi korban atau pelaku cyberbullying.

\section{HASIL DAN PEMBAHASAN}

Literasi digital adalah kemampuan dalam memahami dan menggunakan berbagai informasi dari sumber digital. Kajian ini sudah banyak dipelajari baik oleh akademisi dari Barat maupun dari Asia. Perkembangannya juga cukup pesat dari tahun ke tahun. Hal ini seperti disampaikan oleh Mathar dalam A'yuni yang menyatakan bahwa pada tahun 2014 terdapat 843 artikel tentang literasi digital, di mana 661 artikel diterbitkan dalam Bahasa Inggris (A'Yuni, 2014). Melihat banyaknya artikel tersebut tentu saja memperlihatkan bahwa literasi digital sangat menarik untuk dikaji. Namun pada tataran di lapangan ketidakbijakan dalam menggunakan media masih seringkali ditemui.

Data Cyberbulling Research Center merilis pada tahun 2020 sebanyak 8881 remaja berusia 1118 tahun di Amerika pernah melakukan cyberbullying. Di Indonesia sendiri pelaku cyberbullying begitu mudah kita temui, walau tidak ada data resmi terkait hal tersebut. Setidaknya menurut data kepolisian ada 25 kasus yang dilaporkan setiap harinya. Tentu hal ini merupakan masalah yang serius (Pratama, 2021) karena dampak cyberbullying yang tidak remeh.

Cyberbulling atau perundungan dengan menggunakan digital media merupakan perilaku agresif yang berulang-ulang dengan menakutnakuti, membuat marah, atau mempermalukan korban sasaran. Cyberbullying dapat berdampak pada perasaan depresi, ketidakpercayaan diri, curiga berlebihan terhadap orang lain, kurang motivasi, menarik diri dari lingkungan sosial dan lain-lain.

Kegiatan pertama yang dilakukan adalah menyelenggarakan Webinar seputar literasi digital dan pemahaman akan cyberbullying. Kegiatan diikuti oleh 50 anggota Paguyuban Cacak dan Yuk 
1018 Edukasi Literasi Digital pada Remaja dalam Menangkal Cyberbullying-Merry Fridha Tri Palupi, Fitri Norhabiba

DOI: https://doi.org/10.31004/abdidas.v2i4.408

lumajang dan juga ada 4 peserta dari luar Paguyuban Cacak dan Yuk Lumajang karena acara Webinar diselenggarakan secara terbuka. Berikut merupakan flyer kegiatan:

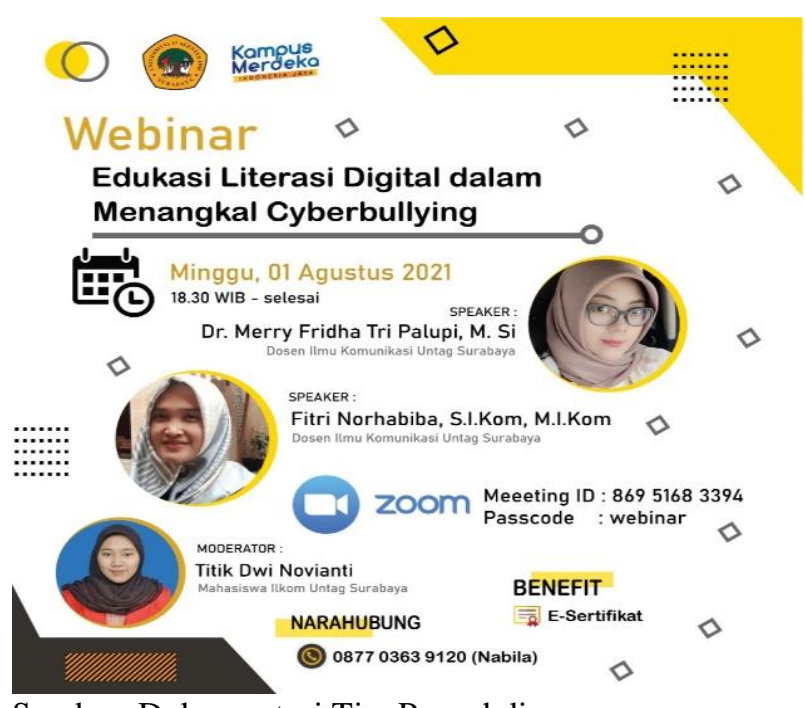

Sumber: Dokumentasi Tim Pengabdian

Gambar 1.Flyer Kegiatan

Kegiatan berlangsung selama dua jam. Materi yang disampaikan dalam Webinar yaitu berupa pemahaman akan literasi digital, bahaya cyberbullying, pemahaman akan UUITE. Selama berjalannya acara, peserta antuasias mengikuti jalannya acara hingga selesai. Sebelum Webinar peserta diminta untuk mengisi pretest dan post-test yang menjadi indikator untuk mengetahui sejauh mana pemahaman peserta terhadap literasi digital dan cyberbullying. Berikut merupakan foto-foto kegiatan:
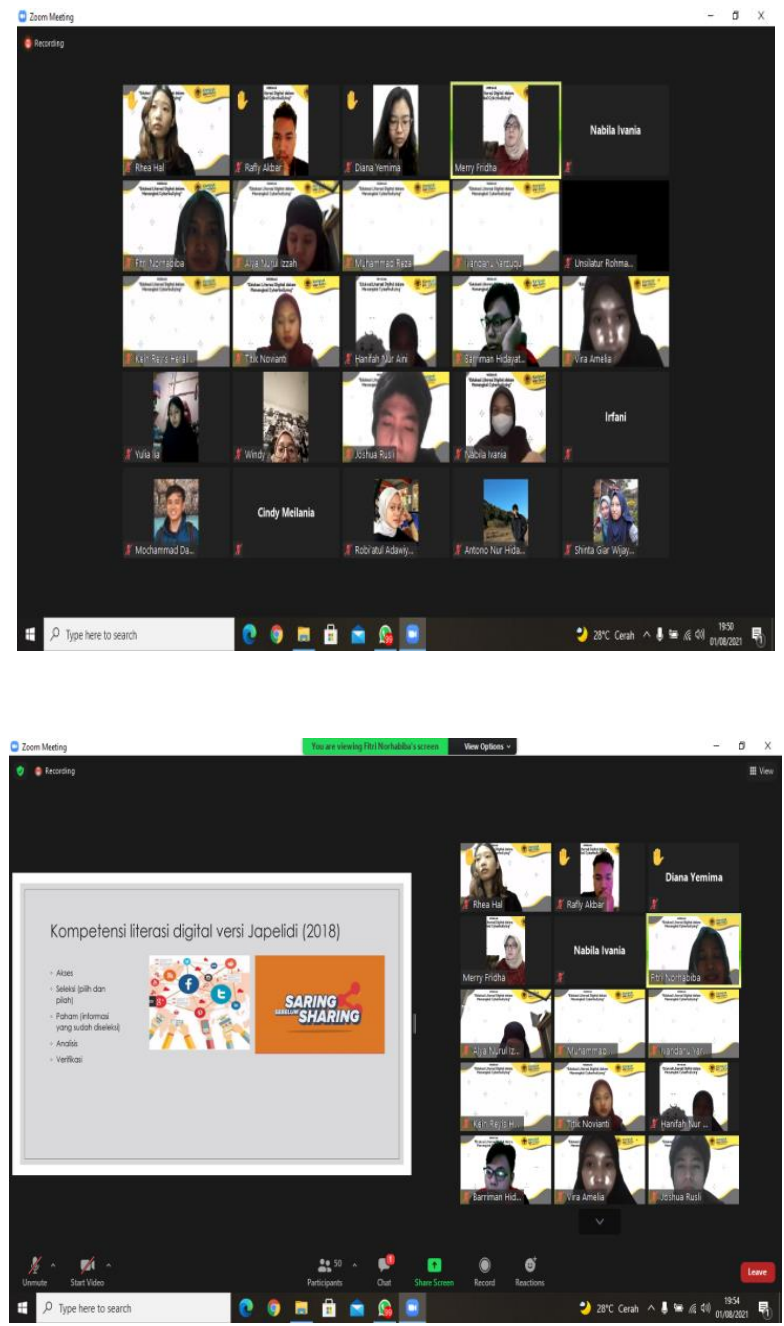

Sumber: Dokumentasi Tim Pengabdi

Gambar 2. Foto Kegiatan Pertama Webinar Edukasi Literasi Digital

Dari hasil pretest, tim mendapatkan data bahwa seluruh peserta merupakan pengguna aktif media sosial yang memiliki lebih dari satu akun media sosial. Sebagai pengguna aktif, kecerdasan menggunakan media digital dianggap sebagai hal yang penting. Hasil pretest terdapat pada tabel berikut ini: 
1019 Edukasi Literasi Digital pada Remaja dalam Menangkal Cyberbullying-Merry Fridha Tri Palupi, Fitri Norhabiba

DOI: https://doi.org/10.31004/abdidas.v2i4.408

Tabel 1. Hasil Pretest

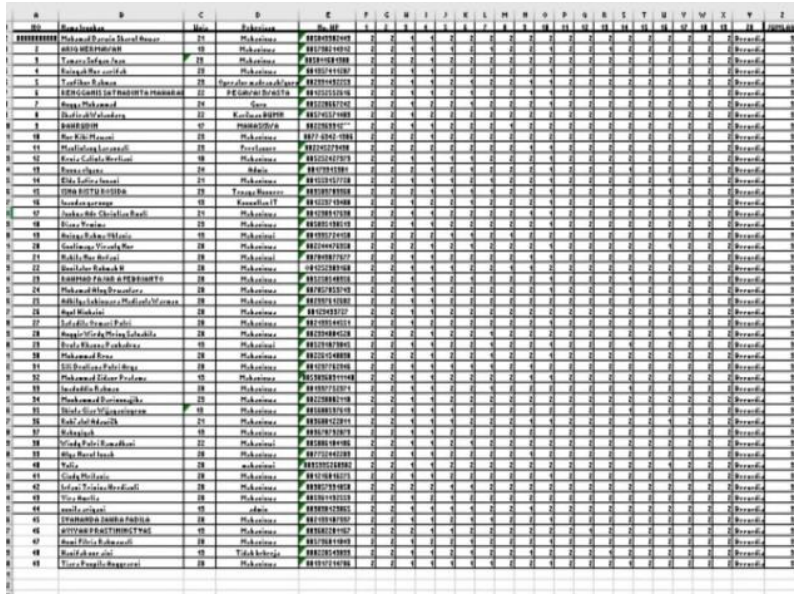

Sumber: Diolah Tim Pengabdi

Walau menyadari literasi digital merupakan hal yang penting, sayangnya pada hasil post-test tedapat 9 orang yang kerap melakukan cyberbulyying, dan 8 peserta yang pernah menjadi korban cyberbullying. Data hasil post-test terdapat pada tabel 2 berikut ini:

Tabel 2. Hasil Post-test

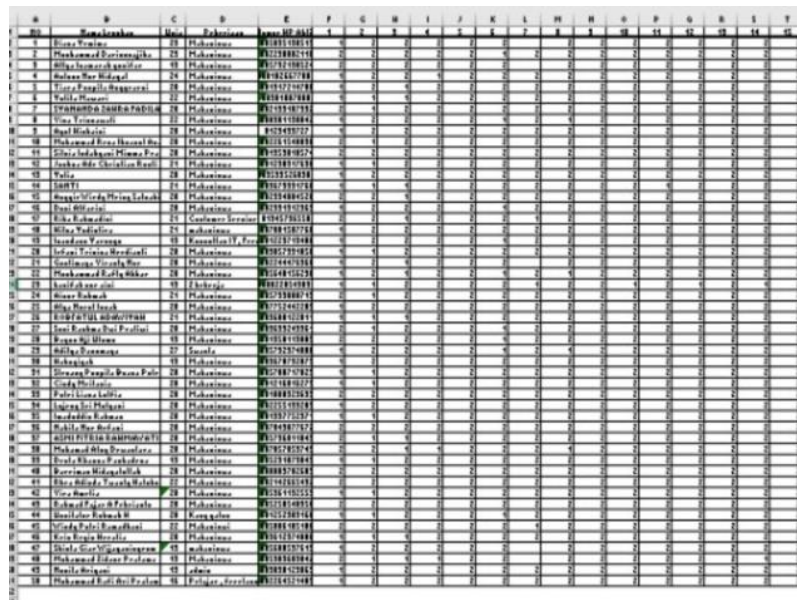

Sumber: Diolah Tim Pengabdi

Pada hasil pretest di atas terdapat 17 orang peserta yang belum memiliki literasi digital. Sehingga 17 orang tersebut menjadi prioritas tim untuk dilakukan kegiatan selanjutnya yaitu sharing session dan pendampingan lebih dalam lagi.

Berikut merupakan dokumentasi acara kedua:

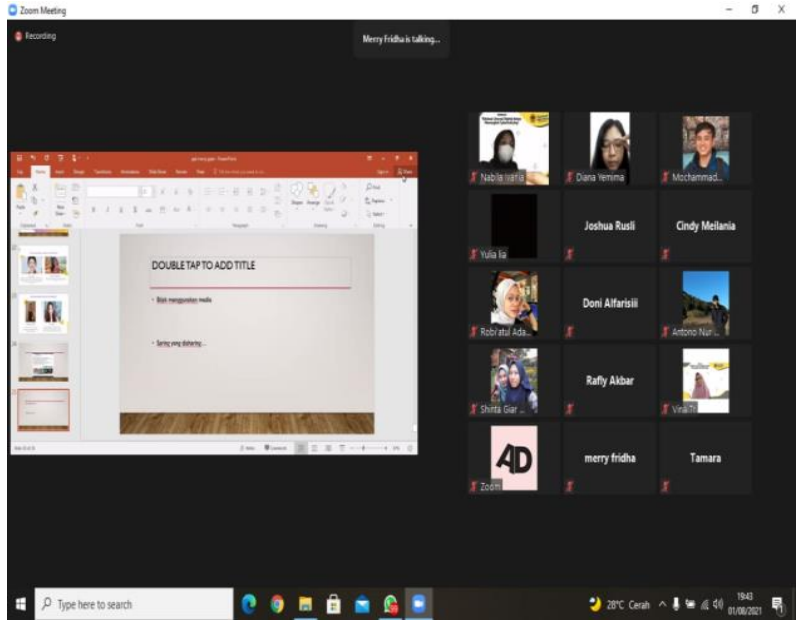

Sumber: Dokumentasi Tim Pengabdian.

Gambar 3. Sharing Session dan Pendampingan

Setelah pendampingan dan sharing session selesai, peserta kembali diminta mengisi post-test. Hasil post-test menunjukkan hasil yang menggembirakan, di mana seluruh peserta lebih memahami akan literasi digital dan mengerti cara menangkal cyberbullying serta bersedia menjadi agen yang mensosialisasikan cyberbullying. Hasil post-test terdapat pada tabel 3 berikut ini:

Tabel 3. Hasil Post-test ke-2

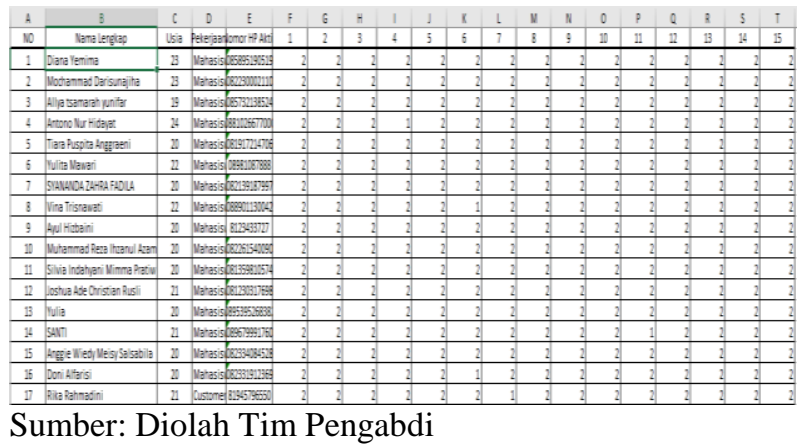

Berdasarkan pada hasil post-test di atas maka kami dapat menyimpulkan bahwa kegiatan 
1020 Edukasi Literasi Digital pada Remaja dalam Menangkal Cyberbullying-Merry Fridha Tri Palupi, Fitri Norhabiba

DOI: https://doi.org/10.31004/abdidas.v2i4.408

ini efektif sebagai salah satu cara dalam menambah pemahaman literasi digital pada mitra kegiatan yaitu Cacak dan Yuk Lumajang.

\section{SIMPULAN}

Dari hasil kegiatan "Edukasi Literasi Digital pada Remaja dalam Menangkal Cyberbullying ini akan menghasilkan kompetensi bukan hanya kemampuan peserta dalam menggunakan teknologi, tapi juga meliputi kemampuan menganalisis, berpikir kritis, sampai dengan kontrol dari penggunaannya yang adiktif serta membuat peserta menjadi lebih bijak dalam menggunakan media digital, dan dapat keluar dari lingkaran cyberbullying. Untuk itu, kegiatan yang demikian pentingnya ini diharap dapat menjadi titik awal lahirnya kader-kader remaja yang akan turut mensosialisasikan literasi digital.

\section{UCAPAN TERIMA KASIH}

Dalam kegiatan pengabdian ini, tim mengucapkan terima kasih tak terhingga kepada TIM LPPM Untag Surabaya atas kesempatan yang diberikan kepada tim pengabdian dan juga kepada mitra kegiatan yaitu Paguyuban Cacak dan Yuk Lumajang atas kerjasama yang baik sehingga kegiatan edukasi literasi digital dalam menangkal cyberbullying ini berjalan dengan lancar.

\section{DAFTAR PUSTAKA}

A’Yuni, Q. Q. (2014). Literasi Digital Remaja Di Kota Surabaya.(Studi Deskriptif Tentang Tingkat Kompetensi Literasi Digital Pada Remaja SMP, SMA dan Mahasiswa di Kota Surabaya. Journal Unair.Ac.Id.

Agustini, P. (2021). KomInfo Targetkan 12,5 juta 